\title{
Análise do Perfil dos Alunos Ingressantes de um Curso de Licenciatura em Química Semipresencial de um Polo do Sistema UAB: Um Guia Acerca das Publicações sobre o Tema em Questão
}

\section{Analysis of Profile of beginners Students of a semi-presential} Education Degree in chemistry of a UAB System pole: A guide to Publications about the Issues in Question

\author{
Érica de Melo Azevedo ${ }^{{ }^{*}}$ \\ 1 Instituto Federal do Rio de Janeiro \\ Campus Duque de Caxias \\ Av .República do Paraguai, 120, \\ Duque de Caxias-RJ. \\ erica.azevedo@ifri.edu.br
}

\section{Resumo}

O presente trabalho tem como objetivo realizar uma análise do perfil dos estudantes ingressantes de um curso de Licenciatura em Química semipresencial de um polo do Sistema UAB. Foram realizadas pesquisas bibliográficas em portais de busca de artigo (Scielo, Google Acadêmico e Portal Capes) acerca de trabalhos publicados sobre licenciatura em Química EAD e/ou semipresenciais em uma primeira etapa. A quantidade de resultados retornados foi muito ampla, porém genérica, já que a maioria dos trabalhos tratava de ensino de Química presencial ou metodologias para ensino de Química. Por isso, procedeu-se a uma busca sobre ensino de Química EaD e/ou semipresencial nos anais de dois congressos nacionais na área de Química. Após essa pesquisa extensa, pode-se concluir que poucos trabalhos têm sido publicados nos dois congressos analisados. Na segunda etapa, foi aplicado um questionário aos alunos ingressantes deste curso. Foram feitas perguntas de cunho econômico, social e opinativo. A partir das respostas dos alunos, foram elaborados gráficos interpretativos, desenvolvendo uma discussão crítica acerca do perfil e da visão dos discentes em e relação às possibilidades, vantagens e desvantagens da modalidade de ensino.

Palavras-chave: Análise do perfil dos estudantes. Licenciatura em Química semipresencial. Análise das publicações. 


\section{Analysis of Profile of beginners Students of a semi- presential Education Degree in chemistry of a UAB System pole: A guide to Publications about the Issues in Question \\ Abstract}

This work aims to carry out an analysis of the profile of beginner students in semi-presential Education degree in Chemistry at a pole of the UAB System. Bibliographic searches were carried out on article search portals (Scielo, Google Scholar and Portal Capes) about published works. Bibliographic searches were carried out on article search portals (Scielo, Google Scholar and Portal Periódicos Capes) about published works. After this extensive research, we can conclude that few papers have been published in the two analyzed Congresses. In the second stage, a questionnaire was applied to beginner students in this course. Economic, social and opinion questions were asked. Based on the students' answers, interpretative graphics were developed, developing a critical discussion about the student's profile and their perspectives concerning possibilities, advantages and disadvantages of the teaching modality.

Keywords: Student profile analysis. Semi-presential Education degree in Chemistry. Publications analysis.

\section{Introdução}

Atualmente, há 193 cursos de Graduação em Licenciatura em Química em funcionamento no Brasil, sendo 23 cursos ofertados na modalidade EaD e 254 na modalidade presencial (estes últimos presentes em todos os Estados brasileiros). O total de matrículas em cursos de Licenciatura em Química EAD em 2018 foi de 6967, sendo que, desse total, quase metade das matrículas foram realizadas em instituições privadas e, do total de matrículas, 2386 foram realizadas por universidades públicas federais (CENSO ABED, 2018).

De acordo com o Conselho Nacional de Educação-CNE (2003), há um déficit de 250 mil docentes em turmas de ensino básico, principalmente nas disciplinas de Física e Química. Além disso, a região Sudeste é a localidade onde mais profissionais ministram aulas de determinada disciplina sem apresentar formação em Licenciatura na área. Um relatório do CNE (2007) aponta uma demanda por profissionais docentes maior que a oferta disponível. Dessa forma, houve necessidade do desenvolvimento de políticas educacionais visando atender a essas demandas, principalmente em zonas rurais e outras cidades mais distantes dos grandes centros.

Houve um aumento significativo da oferta de cursos semipresenciais no Brasil no ano de 2018, em comparação ao ano anterior, passando de 3041 para 7458 cursos. Desse total, 210 cursos ofertados em 2018 eram de Licenciatura. Os cursos de Licenciatura também são os que concentram o maior volume de matrículas EAD/semipresencial. No entanto, apenas uma pequena parcela corresponde a matrículas em cursos na área de Ciências Exatas e da Terra (Censo ABED, 2018).

O primeiro curso de Licenciatura em Química do Brasil foi criado pela USP, em 1934 e fazia parte da Faculdade de Filosofia, Ciências e Letras, a qual era composta, quando da sua criação, pelos cursos de: Filosofia, Ciências (com subseções: Ciências Matemáticas, Ciências Físicas, Ciências Químicas, Ciências Naturais, Geografia e História, Ciências Sociais e Políticas) e Letras. Nessa época, o curso de Química 
durava 3 anos, tempo no qual o formando aprendia a ciência pura, podendo fazer a complementação pedagógica com o Curso de Didática para obter o diploma de Professor Secundário (MESQUITA \& SOARES, 2011; MASSENA, 2010).

No Rio de Janeiro, os cursos de Licenciatura dentro do Sistema UAB são oferecidos pelo Consórcio Centro de Educação a Distância do Rio de Janeiro (CEDERJ), que é, atualmente, a única Instituição que permite o acesso a cursos de Graduação EAD e semipresenciais em Instituições Públicas (INEP, 2018).

O CEDERJ foi fundado em 1999, tendo o primeiro curso iniciado em 2001, em Polos localizados em cidades do interior do Estado do Rio de Janeiro. São ofertados 15 cursos de Graduação semipresenciais, incluindo Licenciatura em Química. São oferecidos dois cursos de Licenciatura em Química, sendo um deles coordenado pela Universidade Federal do Rio de Janeiro (UFRJ) e outro coordenado pela Universidade Federal do Norte Fluminense (UENF) (BIELSCHOWSKY, 2017; AZEVEDO, 2018).

A oferta de cursos de Graduação em Licenciatura em Química EAD é relativamente nova, tendo iniciado em 2005, com a oferta do curso pela Universidade Federal do Rio Grande do Norte (UFRN). O curso ofertado pela UFRJ tem a duração prevista de 9 semestres e as disciplinas são separadas em eixos temáticos, que se desenvolvem a partir de um tema gerador e misturam diferentes áreas da Química na mesma disciplina. Na disciplina Química II, por exemplo, o tema é Combustíveis, e os conhecimentos abordados envolvem uma parte da Química Orgânica I e de Físico Química I (termodinâmica clássica). Os temas geradores são muito importantes na facilitação da contextualização do ensino, já que possibilita ao educando a oportunidade de construir de forma mais significativa sua própria concepção de mundo científico e cultural. No entanto, a maioria dos cursos presenciais de Licenciatura em Química no Brasil não utiliza essa abordagem em sua matriz curricular e as disciplinas são organizadas de forma compartimentada (AZEVEDO, 2018; ALMEIDA et al, 2017; SANTOS et al, 2011).

O curso de Licenciatura em Química do Polo Nova Iguaçu, localizado na baixada fluminense do Estado do Rio de Janeiro, é coordenado pela UFRJ e iniciou seu funcionamento no segundo semestre de 2014 e, até 2019.2, não havia nenhum concluinte. Apesar de o curso ser recente, são escassas as informações a respeito da quantidade de alunos matriculados e alunos formados em outros polos do Consórcio CEDERJ. Este trabalho tem como foco estudar e analisar o perfil dos alunos ingressantes do curso de Licenciatura em Química do Polo Nova Iguaçu, uma vez que houve muita dificuldade em encontrar informações relativas a outros polos nos quais este curso é ofertado. Há escassez, por exemplo, em relação à publicização da quantidade de alunos matriculados, concluintes e formados neste curso de graduação ofertado pelo Sistema UAB no estado do Rio de Janeiro. Ao focar em grupo específico, o autor tem como objetivo divulgar informações e incentivar uma discussão mais ampla sobre os cursos de Licenciatura em Química semipresenciais no meio acadêmico.

A análise do perfil dos alunos ingressantes em cursos de Graduação é uma importante ferramenta para avaliar a efetividade das Políticas Públicas em Educação, o perfil sociológico dos estudantes, perspectivas profissionais dos estudantes, dificuldades apresentadas nessa modalidade de estudo, e permitem, sobretudo, realizar uma avaliação diagnóstica inicial dos ingressantes em relação ao curso de Graduação.

\subsection{Objetivos}

O objetivo do presente trabalho é realizar uma pesquisa acerca do perfil dos alunos ingressantes do curso de Graduação em Licenciatura em Química coordenado pela UFRJ no âmbito do Sistema UAB. A pesquisa foi feita com alunos do Polo Nova Iguaçu e foram avaliados aspectos sociológicos e a percepção dos mesmos sobre o curso. Essa análise será feita em concomitância à avaliação das publicações e pesquisas que tratam de ensino de Química EaD. 


\section{Metodologia}

\subsection{Pesquisa Bibliográfica}

A pesquisa foi separada em duas partes. Primeiro, realizou-se uma busca bibliográfica na base de dados Google Acadêmico, Portal Scielo e Portal Periódicos Capes, usando as palavras-chave "Química CEDERJ" e "Química ensino a distância". Além disso, foram realizadas pesquisas acerca do tema nos anais de dois congressos nacionais na área de Química, conforme será descrito com detalhes na parte de Resultados e Discussão.

Foram avaliados a quantidade de trabalhos retornados e, dentro desse total, a quantidade de artigos que tratavam do tema ensino de Química no âmbito EaD ou semipresencial. O objetivo desta etapa é compreender as temáticas e abordagens das publicações sobre o ensino de Química na modalidade EaD e semipresencial.

\subsection{Questionário para os alunos ingressantes}

A segunda parte da pesquisa constituiu da aplicação de um questionário avaliativo com 8 questões, sendo 7 de múltipla escolha e 1 discursiva, conforme é apresentado a seguir. O questionário foi aplicado para os alunos na data da aula inaugural, em 2019.1, momento no qual é apresentado o Consórcio CEDERJ, o Sistema UAB, os diretores e mediadores presenciais e mediadores coordenadores dos cursos de Graduação e toda a estrutura do sistema de educação a distância no qual o aluno está inserido. Foram analisadas as respostas de 28 participantes.

1. Qual o seu gênero?

Feminino

Masculino

Outros

2. Qual a sua faixa etária?

$<18$ anos

18-24 anos

25-30 anos

31-35 anos

$>35$ anos

3. Qual o seu nível de formação?

Ensino médio regular

Ensino médio modalidade EJA

Ensino médio-técnico na área de Química

Ensino médio-técnico em outras áreas

Graduação incompleta/concomitante

Graduação

Pós-graduação

4. Quando você concluiu o Ensino médio?

2018

2014-2017

2010-2013 
2006-2009

Antes de 2006

5. Qual a sua experiência com cursos na modalidade EaD e/ou semipresencial? Nenhuma

Já participei de cursos de extensão

Já cursei outra graduação nesta modalidade

Já cursei pós-graduação nesta modalidade

6. Por que você escolheu o CEDERJ para fazer a sua graduação?

Flexibilidade de horários

Melhor custo-benefício

Devido à distância entre sua residência e a Instituição de Ensino

Outra justificativa:

7. Qual a melhor alternativa que descreve sua situação de trabalho hoje em dia?

Não estou trabalhando (desempregado)

Não estou trabalhando (estou me dedicando apenas aos estudos)

Trabalho na área de Química

Trabalho em outras áreas

Trabalho eventualmente

8. Na sua opinião, qual (is) a(s) principal (is) diferença (s) entre o ensino presencial e a modalidade EAD?

\section{Resultados e Discussão}

\subsection{Pesquisa nas bases de dados}

Primeiramente, o autor gostaria de destacar a importância e o objetivo de apresentar a pesquisa nas bases de dados sobre o assunto que está sendo discutido. Ao publicizar esta informação, é possível compreender quais os assuntos que foram mais discutidos e explorados no ensino de Química EaD/semipresencial, permitindo aos pesquisadores que desejem iniciar e/ou publicar a possibilidade de discussões mais relevantes e inovadoras, ampliando as perspectivas. Outros aspectos podem se mostrar igualmente relevantes quando se mostra em quais estados e universidades as pesquisas sobre o assunto estão sendo mais publicadas, permitindo a busca por parcerias e a avaliação dos locais onde as Políticas Públicas para a formação de professores de Química nesta modalidade estão sendo implementadas.

A pesquisa na base de dados foi realizada com termos em Português. A quantidade de trabalhos publicados sobre educação a distância é significativa, porém ampla; por isso, foram retornados uma quantidade grande de trabalhos. No entanto, foram encontradas poucas publicações sobre cursos de Química a distância e ensino de Química EaD.

Ao pesquisar as palavras-chave "Química CEDERJ" no Google Scholar, foram encontradas 1250 publicações, mas a maioria não tratava de ensino de Química no âmbito do CEDERJ, tratando-se apenas de publicações sobre o Consórcio ou ensino de Química presencial. A razão para a realização da pesquisa no âmbito do CEDERJ é devido ao fato de este ser o maior Consórcio de Universidades Públicas do País que oferece cursos semipresenciais em Licenciatura em Química.

No Portal Periódicos Capes, foram encontradas 7 publicações, mas nenhuma tratava de ensino de Química. No Portal Scielo, não foi encontrada nenhuma publicação. 
O uso das palavras-chave "Química ensino a distância" retornou uma quantidade de publicações ainda maior, cerca de 141 mil. Nesse caso, a abordagem dos trabalhos encontrados foi extremamente diversificada: foram encontrados trabalhos que tratavam de ensino de Química presencial, ensino de Química a distância e práticas docentes para a aprendizagem da disciplina no ensino básico. No portal Capes, foram retornados 430 publicações, com uma quantidade significativa de publicações sobre metodologias para ensino de Química. O portal Scielo retornou 3 publicações, mas nenhuma tratava do assunto em questão.

A quantidade de trabalhos retornados a partir dessa pesquisa foi muito ampla e genérica; por isso, realizou-se uma pesquisa nos anais dos dois principais eventos nacionais de Química, a Reunião Anual da Sociedade Brasileira de Química (RASBQ), organizado pela Sociedade Brasileira de Química (SBQ), e o Congresso Brasileiro de Química (CBQ), organizado pela Associação Brasileira de Química (ABQ). Ambos os eventos anuais apresentam uma seção dedicada ao Ensino de Química, e a consulta foi feita aos Anais de 2015-2019 dos eventos na seção indicada (Tabela 1). Esse recorte temporal foi realizado na tentativa de retornar uma quantidade de resultados que fosse possível analisar. Na RASBQ, foram encontrados dois trabalhos que remetem ao ensino de Química a distância. Um dos trabalhos trata da aplicação de uma metodologia de aprendizagem construtivista utilizando um Ambiente Virtual de Aprendizagem (AVA) em um curso EaD, e o outro trata do uso de uma AVA na metodologia de aprendizagem por desafios em um curso presencial. Como se pode observar, apesar de tratar de uma metodologia para ensino a distância, o termo não aparece nem nos títulos, nem nas palavras-chave, mostrando que o foco dos trabalhos não é a educação a distância, mas o uso de TICs (Tecnologias de Informação e Comunicação), metodologias de ensino e na natureza da argumentação científica.

No CBQ, foram encontrados 13 trabalhos, sendo a maioria relacionado ao uso de Objetos Virtuais de Aprendizagem (OVAs) em cursos presenciais de nível médio, uso de TICs e AVAs em ensino híbrido.

A escassez na publicação do ensino de Química a distância nos dois Congressos analisados se dá devido à recente implementação desses cursos e da natureza experimental do estudo e da formação Química. A maior parte dos trabalhos publicados foram desenvolvidos por pesquisadores do Estados do Maranhão, Goiás, Mato Grosso do Sul e Mato Grosso. Uma possível explicação para a participação ativa dos pesquisadores nessas regiões é a implementação de políticas públicas e desenvolvimento de metodologias para a formação de professores de Química em regiões cuja oferta de docentes é menor que a demanda por esses profissionais.

Tabela 1: Trabalhos abordando a temática educação a distância em ensino de Química publicados em Anais do Congresso Brasileiro de Química e Reunião Anual da Sociedade Brasileira de Química no período $2015-2019$.

\begin{tabular}{|l|l|l|}
\hline Título do Trabalho & Evento & Instituição de Ensino \\
\hline $\begin{array}{l}\text { Objetos digitais de aprendizagem utilizados } \\
\text { pelos professores do Estado do Mato Grosso } \\
\text { do Sul }\end{array}$ & CBQ & $\begin{array}{l}\text { Universidade Federal da Grande } \\
\text { Dourados (UFGD) }\end{array}$ \\
\hline $\begin{array}{l}\text { O uso de laboratórios virtuais no ensino de Quí- } \\
\text { mica como recurso facilitador na aprendizagem } \\
\text { de alunos do ensino médio da rede pública de } \\
\text { ensino em São Luís - MA }\end{array}$ & CBQ & $\begin{array}{l}\text { Instituto Federal do Maranhão } \\
\text { (IFMA), SEEDUC-MA }\end{array}$ \\
\hline $\begin{array}{l}\text { Objetos digitais de aprendizagem utilizados } \\
\text { pelos professores do estado do Mato Grosso }\end{array}$ & CBQ & UFGD \\
\hline $\begin{array}{l}\text { O uso das redes sociais, facebook e whatsapp, } \\
\text { como ambientes virtuais de aprendizagem }\end{array}$ & CBQ & $\begin{array}{l}\text { Universidade Federal do Ceará } \\
\text { (UFC) }\end{array}$ \\
\hline $\begin{array}{l}\text { Desenvolvimento de um objeto de aprendizagem } \\
\text { para o ensino de Cinética Química }\end{array}$ & CBQ & $\begin{array}{l}\text { Universidade Federal do Mara- } \\
\text { nhão (UFMA) }\end{array}$ \\
\hline
\end{tabular}




\begin{tabular}{|l|l|l|}
\hline $\begin{array}{l}\text { Grupo focal virtual: uma estratégia na educação } \\
\text { básica para o ensino de Química }\end{array}$ & CBQ & $\begin{array}{l}\text { Universidade Federal de Uberlân- } \\
\text { dia (UFU) }\end{array}$ \\
\hline $\begin{array}{l}\text { Ensino híbrido: possibilidades para ensino } \\
\text { interdisciplinar }\end{array}$ & CBQ & $\begin{array}{l}\text { Universidade Franciscana (UNI- } \\
\text { FRA), Instituto Federal de Educa- } \\
\text { ção Ciência e Tecnologia Farroupi- } \\
\text { Iha (IFFAR) }\end{array}$ \\
\hline $\begin{array}{l}\text { Desenvolvimento de um objeto de aprendizagem } \\
\text { para o ensino de eletrólise }\end{array}$ & CBQ & $\begin{array}{l}\text { Universidade Federal do Mara- } \\
\text { nhão (UFMA) }\end{array}$ \\
\hline $\begin{array}{l}\text { Abordagem em educação ambiental } \\
\text { no curso de licenciatura em Química, } \\
\text { modalidade EaD }\end{array}$ & CBQ & $\begin{array}{l}\text { Instituto Federal do Mato Grosso } \\
\text { (IFMT) }\end{array}$ \\
\hline $\begin{array}{l}\text { Desenvolvimento de um objeto de aprendizagem } \\
\text { para o ensino de soluç̃̃es }\end{array}$ & CBQ & $\begin{array}{l}\text { Universidade Estadual do Rio } \\
\text { Grande do Sul (UERGS), UFMA, }\end{array}$ \\
\hline $\begin{array}{l}\text { Desenvolvimento de um objeto de aprendizagem } \\
\text { para a identificação dos átomos de carbono e } \\
\text { classificação da cadeia carbônica em compostos } \\
\text { orgânicos }\end{array}$ & CBQ & UERGS, UFMA \\
\hline $\begin{array}{l}\text { Estudos da aplicação de um objeto virtual de } \\
\text { aprendizagem para a experimentação no ensino } \\
\text { de Química }\end{array}$ & CBQ & $\begin{array}{l}\text { Universidade Federal de Goiás } \\
\text { (UFGO), Centro de Ensino e Pes- } \\
\text { quisa Aplicada à educação (CEPAE) }\end{array}$ \\
\hline $\begin{array}{l}\text { A utilização do ambiente virtual no ensino de } \\
\text { Química: um estudo de caso na escola-campo do } \\
\text { programa residência pedagógica }\end{array}$ & CBQ & $\begin{array}{l}\text { Universidade Federal do Pará } \\
\text { (UFPA) }\end{array}$ \\
\hline $\begin{array}{l}\text { Natureza e qualidade conceitual de } \\
\text { argumentos em um ambiente virtual } \\
\text { de aprendizagem }\end{array}$ & RASBQ & $\begin{array}{l}\text { Universidade Metropolitana de } \\
\text { Santos (Unimes) }\end{array}$ \\
\hline $\begin{array}{l}\text { Objetos Digitais de Aprendizagem no } \\
\text { a formação dos licenciandos em } \\
\text { Química em EaD }\end{array}$ & Universidade de São Paulo (USP) \\
\hline
\end{tabular}

Fonte: autoria própria

\subsection{Análise do Perfil dos estudantes ingressantes}

A pesquisa realizada mostra que a maioria dos alunos ingressantes no curso é do sexo feminino e a faixa etária predominante é entre 18 e 24 anos. Se considerada a faixa etária de 18 a 30 anos, o percentual chega a 53,5\%. Apesar de a amostragem disponível ter sido pequena, o Censo da Associação Brasileira de Educação a Distância (ABED) de 2018 mostra que esses resultados são relativamente próximos.

Quando se trata de cursos totalmente a distância, a distribuição é um pouco diferente. Segundo o Censo da ABED (2018), a maior parte dos alunos desta modalidade tem entre 26 e 40 anos. Como se pode observar, a faixa etária predominante dos alunos aumenta, uma vez que o curso semipresencial exige que o aluno vá até os polos para realizar algumas atividades, e a tendência é que os mais jovens estejam mais disponíveis para essas atividades. É importante destacar que nesses números não estão incluídos os cursos Livres, como cursos de Extensão e Qualificação. 


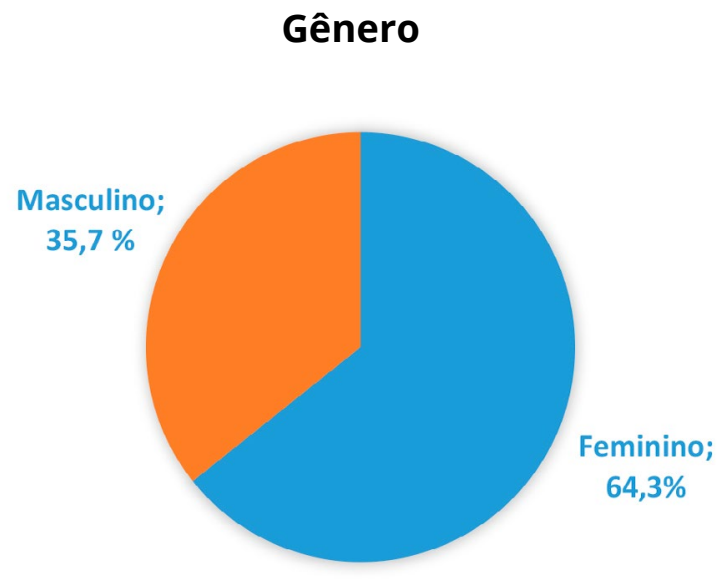

\section{Faixa etária}

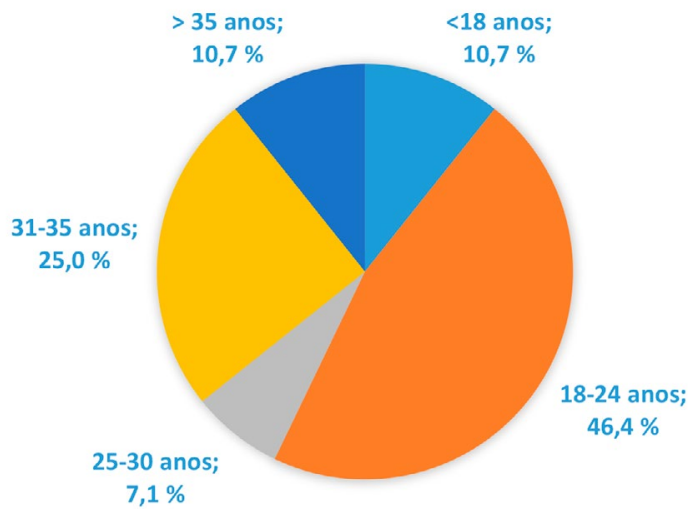

Figura 1: Respostas dos alunos ingressantes para gênero e faixa etária.

Fonte: Autoria Própria.

No que diz respeito à formação prévia dos alunos ingressantes, observa-se que a maior parte (57\%) cursou Ensino Médio-Técnico na área de Química ou Ensino Médio Regular, estando uma parcela menor, porém significativa, cursando outra Graduação ou com Graduação Incompleta. O contato com disciplinas da área de Química se mostra um fator relevante para a escolha do curso de Graduação. Nesse caso, entende-se que a Graduação incompleta se refere a matrículas trancadas ou abandonadas.

\section{Nível de formação}

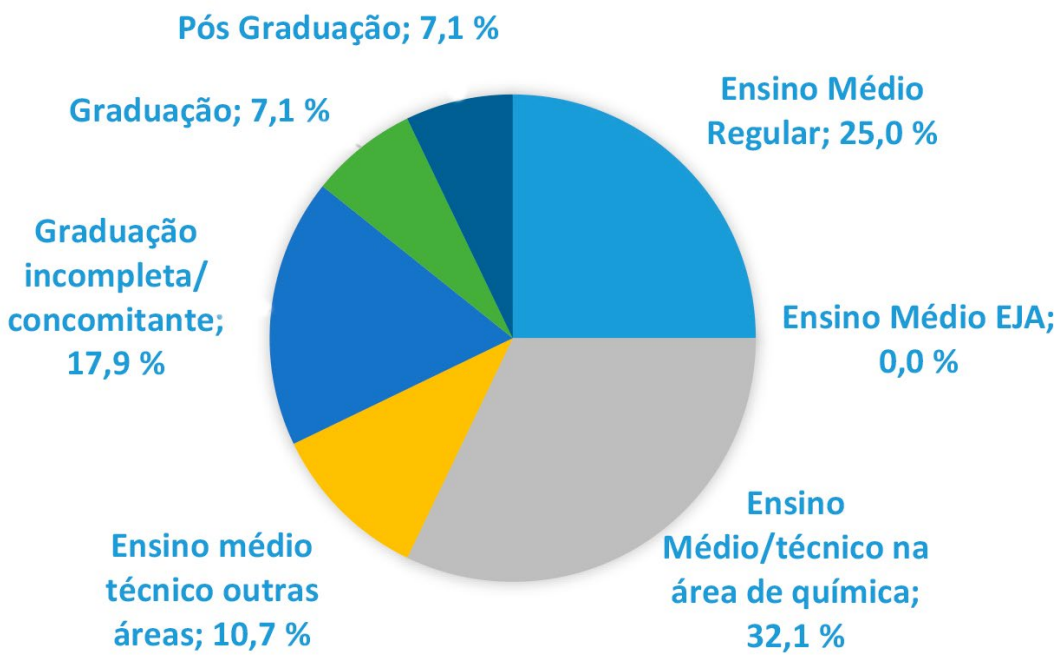

Figura 2: Respostas dos alunos ingressantes para formação prévia.

Fonte: Autoria Própria.

A modalidade a distância e semipresencial exige muita disciplina, flexibilidade de horários e disponibilidade de estudos. A falta de experiência e de estratégias para estudar, aliada à subestimação dos cursos semipresenciais, pode ser um dos fatores que levam à evasão média entre 26 e $50 \%$ da maioria dos cursos. Nos cursos presenciais, o percentual médio de evasão é de 8,7\% (COLPANI, 2018). Segundo Baltar e Silva (2017), as causas da evasão são classificadas em categorias: situacional, falta de apoio acadêmico, problemas com tecnologia, falta de apoio administrativo e sobrecarga de trabalho. O fator situacional está relacionado a problemas pessoais, que incluem problemas de saúde e familiares. A falta de apoio acadêmico está relacionada à pouca interação entre aluno e tutor, ou aluno e professor, que se 
exemplifica pela falta de feedback e falta de apoio da Instituição (FARIA \& FRANCO, 2011; ASSUMPÇÃO, RAMADA \& CASTRO, 2018).

Os problemas com a tecnologia podem estar relacionados ao acesso à internet, computadores ou falta de conhecimentos mínimos para o uso das tecnologias. A sobrecarga de trabalho é um fator endógeno, que se reflete na falta de tempo para dedicação aos estudos. Os fatores que mais influenciam a evasão dos cursos, entre os listados acima, variam muito de acordo com a região na qual o curso é ofertado, tipo de curso de Graduação (Licenciatura, Bacharelado, Tecnólogo) e a área de conhecimento (VELOSO \& ALMEIDA, 2002; SENTER \& RAYMUNDO, 2018; FERREIRA \& ELIA, 2013).

A análise do questionário mostra que a maioria dos ingressantes não apresenta nenhuma experiência em estudar por esta modalidade. Apenas um pequeno percentual dos ingressantes respondeu que possui experiência em cursos de extensão, cursos de pós-graduação ou outro curso de graduação nessa modalidade. A falta de experiência em estudar nesta modalidade não necessariamente é um fator relevante para ingressar no curso, mas pode ser um fator importante para sua continuidade, devido à alta evasão do curso no Polo em questão.

A maioria dos alunos ingressantes respondeu que terminou o ensino médio entre 2014-2017, e uma parcela menor, porém significativa, respondeu que terminou o ensino médio antes de 2006. Este último grupo inclui os alunos ingressantes com mais de 35 anos, como esperado.

\section{Ano de conclusão do Ensino Médio}

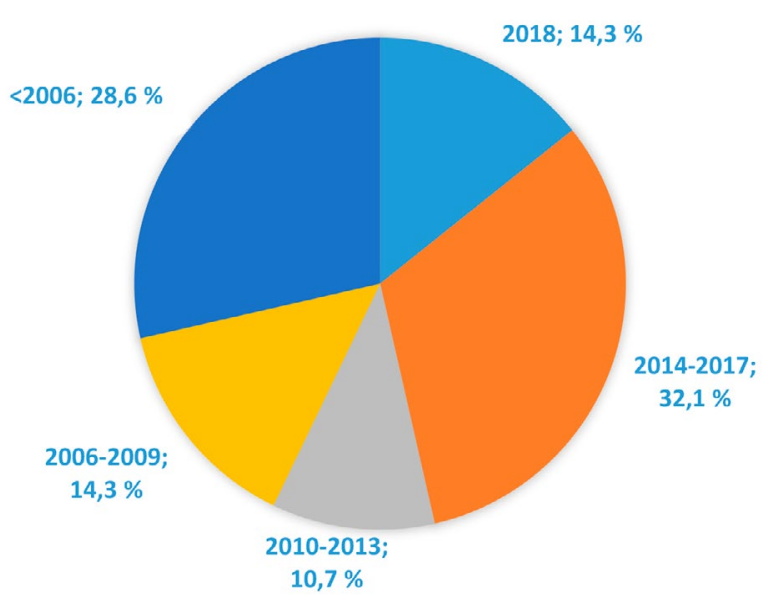

\section{Experiências em cursos EAD}

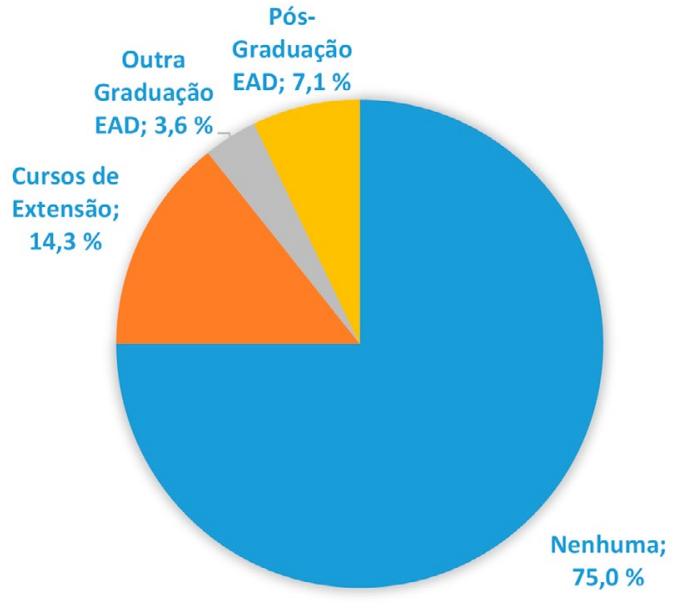

Figura 3: Respostas dos alunos ingressantes para ano de conclusão Ensino Médioe experiência prévia em estudo modalidade EaD.

Fonte: Autoria Própria.

Apesar dos perfis variados em relação à faixa etária e nível de formação, a maioria dos alunos respondeu que a escolha do curso semipresencial foi devido à flexibilidade de horários $(71,4 \%)$ e melhor custo-benefício, uma vez que a frequência nas tutorias presenciais não é obrigatória. No entanto, a frequência mínima de $75 \%$ é obrigatória nas atividades práticas das disciplinas de Química, Física e em algumas disciplinas pedagógicas.

O perfil de trabalho dos participantes mostrou um caráter variado, estando dividido entre emprego em outras áreas, emprego na área de Química e desempregados. Isso pode ser uma indicação de que a escolha do curso semipresencial apresenta uma grande variedade acerca das condições socioeconômicas dos estudantes. 


\section{Porque escolheu o CEDERJ?}

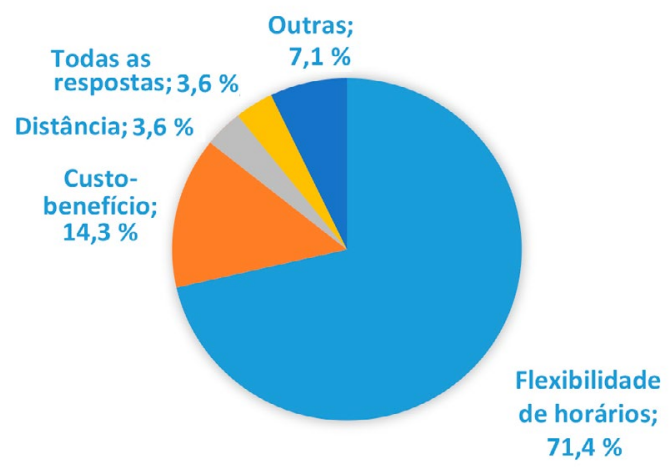

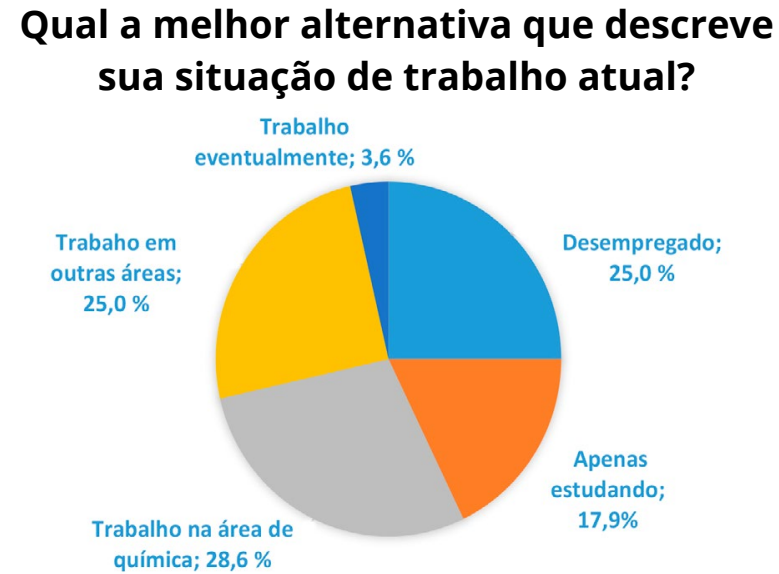

Figura 4: Respostas dos participantes para e escolha da modalidade EaD no CEDERJ e a situação de trabalho atual.

Para a pergunta a respeito da opinião entre as diferenças observadas entre a modalidade EaD e a modalidade presencial, a maioria dos estudantes apresentou ideia clara no que diz respeito aos benefícios em relação à flexibilidade de horários e autonomia para estudos, melhor custo-benefício, mas também fatores que podem dificultar a continuidade, como organização e disciplina para estudar.

\section{Conclusão}

Publicações sobre ensino de Química EaD/semipresencial ainda são escassas, e isso pode ser comprovado a partir da pesquisa bibliométrica realizada nos portais de pesquisa citados. Além da pesquisa nesses portais, foi realizada uma pesquisa bibliométrica em anais de dois Congressos Nacionais de Química sobre a temática abordada. Os trabalhos encontrados foram apresentados em forma de tabela, de forma a publicizar e guiar futuras discussões que tenham como objetivo fomentar e incentivar a pesquisa no âmbito do ensino de Química a distância/semipresencial.

O autor ressalta a dificuldade em encontrar informações quantitativas sobre quantidade de alunos formados, concluintes e matriculados nos cursos de Licenciatura em Química do sistema UAB no Estado do Rio de Janeiro. Espera-se que, futuramente, essas informações estejam divulgadas para a sociedade.

A partir da realização deste trabalho, foi possível desenvolver uma análise crítica dos alunos de um curso de Licenciatura em Química semipresencial, de forma a conhecer o perfil dos alunos ingressantes, suas aspirações, conhecimentos prévios sobre a metodologia EaD e as razões para a escolha dessa modalidade. Em relação à pesquisa acerca das publicações, observou-se uma escassez sobre publicações do tema, mostrando que ainda é necessário conhecer melhor a estrutura dos cursos semipresenciais de Licenciatura em Química, avaliando aspectos em relação ao perfil dos estudantes, metodologias para ensino e dados quantitativos e qualitativos a respeito dos discentes.

\section{Referências Bibliográficas}

ALMEIDA, W. S. B.; LEÃO, M. F.; OLIVEIRA, E. C.; DEL PINO, J. C. Oferta de Cursos de Licenciatura em Química no Brasil e Breve Histórico desses Cursos em Mato Grosso. EaD em Foco, v.7, n.3, p.66-76, 2017. Associação Brasileira de Educação a Distância-ABED. Censo EaD BR: Relatório Analítico da aprendizagem a distância no Brasil 2018. Curitiba: InterSaberes, 2019. Disponível em: http://abed.org.br/arquivos/ CENSO_DIGITAL_EAD_2018_PORTUGUES.pdf 
ASSUMPÇÃO, G de S.; HAMADA, P. C.; CASTRO, A de C. Análise do perfil dos alunos do primeiro curso de EaD em Engenharia de Produção em Instituição de Ensino Superior Pública. Revista Científica Eletrônica de Engenharia de Produção. v.18, n.2, p.404-423, 2018.

AZEVEDO, É. M. A. Importância Da Experimentação Em Cursos De Graduação Em Química Modalidade EaD. In: CONGRESSO INTERNACIONAL DE EDUCAÇÃO E TECNOLOGIAS/ENCONTRO DE PESQUISADORES EM EDUCAÇÃO A DISTÂNCIA, 2018, São Carlos. Anais....SEAD: Universidade Federal de São Carlos, 2018.p.1-11.Disponível em: https://cietenped.ufscar.br/submissao/index.php/2018/article/view/333. Acesso em: 14 maio 2020.

BALTAR, P. C.; SILVA, S. S. Um olhar acerca da evasão na educação a distância. Revista Uniabeu, v.10, n. 4, p.61-67, 2017.

BERNARDES, P. O. et al. Grupo focal virtual: uma estratégia na educação básica para o ensino de Química. In: CONGRESSO BRASILEIRO DE QUÍMICA, 57., 2017, Gramado. Resumos...Gramado: Associação Brasileira de Química, 2017.p-1-1.

BIELSCHOWSKY, C. Consórcio CEDERJ: A História da Construção do Projeto. EaD em Foco, v.7, n.2, p. 8-2, 2017.

BRASIL. Ministério da Educação. Relatório CNE /CEB de Maio de 2007. Relatório produzido para estudar medidas que visem a superar o déficit docente no Ensino Médio-Escassez de professores no Ensino Médio: Propostas estruturais e emergenciais. Portal Ministério da Educação (MEC).

BRASIL. Ministério da Educação. Relatório CNE /CEB de Maio de 2003. Escassez de professores no ensino médio: soluções emergenciais e estruturais. Portal Ministério da Educação (MEC).

COLPANI, R. Educação a Distância: Identificação dos Fatores que Contribuíram para a Evasão dos Alunos no Curso de Gestão Empresarial da Faculdade de Tecnologia de Mococa. EaD em Foco, v.8, n.1, p.1-13, 2018.

FARIA, M. F. B.; FRANCO, A. L. Causas da evasão em curso de graduação a distância em administração em uma universidade pública federal. Revista Teoria e Prática da Educação, v.14, n.3, p.43-56, 2011.

FERREIRA, V. S.; ELIA, M. F. Uma modelagem conceitual para apoiar a identificação das causas da evasão escolar em EaD. In: CONGRESSO BRASILEIRO DE INFORMÁTICA NA EDUCAÇÃO/WORKSHOP DE INFORMÁTICA NA ESCOLA, 2., 2013, Campinas. Resumos... Campinas: Sociedade Brasileira de Computação, 2013. p.399-408.

GONÇALVES, C. C. S. A.; GONÇALVES, A. O. DESAFIOS DA EDUCAÇÃO A DISTÂNCIA: O TUTOR EM FOCO. In: CONGRESSO NACIONAL DE EDUCAÇÃO (EDUCERE), 10., 2011, Curitiba. Resumos... Curitiba: PUCPR, 2011, p.1-1.

KAFER, G. A. et al. Ensino híbrido: possibilidades para ensino interdisciplinar. In: CONGRESSO BRASILEIRO DE QUÍMICA, 57., 2017, Gramado. Resumos... Gramado: Associação Brasileira de Química, 2017.p-1-1.

LIMA, J. B. et al. Desenvolvimento de um objeto de aprendizagem para o ensino de eletrólise. In: CONGRESSO BRASILEIRO DE QUÍMICA, 57., 2017, Gramado. Resumos... Gramado: Associação Brasileira de Química, 2017.p-1-1.

LIMA, J. B. et al. Desenvolvimento de um objeto de aprendizagem para o ensino de cinética Química. In: CONGRESSO BRASILEIRO DE QUÍMICA, 56., 2016, Belém. Resumos... Belém: Associação Brasileira de Química, 2016.p-1-1.

LIMA, J. B. et al. Desenvolvimento de um objeto de aprendizagem para o ensino de soluções. In: CONGRESSO BRASILEIRO DE QUÍMICA, 58., 2018, São Luís. Resumos... São Luís: Associação Brasileira de Química, 2018.p-1-1.

LIMA, J. B. et al. Desenvolvimento de um objeto de aprendizagem para a identificação dos átomos de 
carbono e classificação da cadeia carbônica em compostos orgânicos. In: CONGRESSO BRASILEIRO DE QUÍMICA, 58., 2018, São Luís. Resumos... São Luís: Associação Brasileira de Química, 2018.p-1-1.

MARQUES, G. N.; PEREIRA, S. N.; COSTA, A. C. O uso de laboratórios virtuais no ensino de Química como recurso facilitador na aprendizagem de alunos do ensino médio da rede pública de ensino em são luís - MA. IN: CONGRESSO BRASILEIRO DE QUÍMICA, 55., 2015, Goiânia. Resumos... Goiânia: Associação Brasileira de Química, 2015.p-1-1.DO

MASSENA, E. P. História do currículo da licenciatura em Química da UFRJ: tensões, contradições e desafios dos formadores de professores (1993-2005). 2010. 367 f. Tese (Doutorado em Educação) UFRJ/Faculdade de Educação/Programa de Pós-Graduação em Educação, Rio de Janeiro, 2010.

MESQUITA, A. da S.; SOARES, M. H. F. B. Intencionalidades Reveladas: análise dos diálogos estabelecidos na elaboração conjunta de um projeto pedagógico de curso de licenciatura em Química. Revista de Educação em Ciência e Tecnologia, v.4, n.1, p.3-25, 2011.

MESQUITA, N. A da S.; SOARES, M. H. F. B. Aspectos históricos dos cursos de licenciatura em Química no Brasil nas décadas de 1930 a 1980. Química Nova na escola, v.1, n.34, p.32-37, 2011.

PINTO, B .C. et al. A utilização do ambiente virtual no ensino de Química: um estudo de caso na escola campo do programa residência pedagógica. In: CONGRESSO BRASILEIRO DE QUÍMICA, 59., 2019, João Pessoa. Resumos...João Pessoa: Associação Brasileira de Química, 2019.p-1-1.

RUELA, B. A. et al. ESTUDOS DA APLICAÇÃ̃ DE UM OBJETO VIRTUAL DE APRENDIZAGEM PARA A EXPERIMENTAÇÃO NO ENSINO DE QUÍMICA. In: CONGRESSO BRASILEIRO DE QUÍMICA, 59., 2019, João Pessoa. Resumos...João Pessoa: Associação Brasileira de Química, 2019. p-1-1.

SANTOS, G. A. et al. A formação de professores de Química a distância - estudo preliminar. In: REUNIÃO ANUAL DA SOCIEDADE BRASILEIRA DE QUÍMICA, 34., 2011, Florianópolis. Resumos...Florianópolis: Sociedade Brasileia de Química, 2011. p.1-1.

SENTER, L.; RAYMUNDO, G. M. C. Desafios na implantação de Cursos a Distância. EAD em Foco, v.8, n.1, p.1-14, 2018.

SILVA, A. L.; PEREIRA, S. A.; MUNCHEN, S.; GENEROSO, M. Objetos digitais de aprendizagem utilizados pelos professores do estado do Mato Grosso. In: CONGRESSO BRASILEIRO DE QUÍMICA, 56., 2016, Belém. Resumos... Belém: Associação Brasileira de Química, 2016.p-1-1.DO

SILVA, C. R. F.; SANTOS, A. L. S.; REIPERT, É. C. D.; SILVA, G. N. Objetos Digitais de Aprendizagem no Ensino de Química: investigação preliminar sobre a formação dos licenciandos em Química em EaD. In: REUNIÃO ANUAL DA SOCIEDADE BRASILEIRA DE QUÍMICA, 39., 2016, Goiânia. Resumos... Goiânia: Sociedade Brasileira de Química, 2016.p.1-1.

SILVA, L. A.; SANTOS, P. A.; MUNCHEN, S.; GENEROSO, M. Objetos digitais de aprendizagem utilizados pelos professores do estado do Mato Grosso do Sul. 55., 2015, Goiânia.Resumos... Goiânia: Associação Brasileira de Química, 2015.p-1-1.

SOUZA, M. M. S.; SILVA, A. M. O uso das redes sociais, facebook e whatsapp, como ambientes virtuais de aprendizagem. In: CONGRESSO BRASILEIRO DE QUÍMICA, 56., 2016, Belém. Resumos... Belém: Associação Brasileira de Química, 2016.p-1-1.

SOUZA, N. dos S.; CABRAL, P. F. de O.; QUEIROZ, S.L. Natureza e qualidade conceitual de argumentos em um ambiente virtual de aprendizagem. In: REUNIÃO ANUAL DA SOCIEDADE BRASILEIRA DE QUÍMICA, 39., 2016, Goiânia. Resumos... Goiânia: Sociedade Brasileira de Química, 2016.p.1-1.

VELOSO, T. C.; ALMEIDA, E. P. Evasão nos cursos de graduação da Universidade Federal de Mato Grosso, Campus Universitário Cuiabá. Periódico do Mestrado em Educação da UCDB, n.13, p.133-148, 2002. 